\title{
Vitamin D exposure during pregnancy, but not early childhood, is associated with risk of childhood wheezing
}

\author{
L. N. Anderson, Y. Chen, J. A. Omand, C. S. Birken, P. C. Parkin, \\ T. To, J. L. Maguire and the TARGet Kids Collaboration
}

Version Post-print/accepted manuscript

\author{
Citation Anderson, L., Chen, Y., Omand, J., Birken, C., Parkin, P., To, T., \& \\ (published version) Maguire, J. (2015). Vitamin D exposure during pregnancy, but not early \\ childhood, is associated with risk of childhood wheezing. Journal of \\ Developmental Origins of Health and Disease, 6(4), 308-316. \\ doi:10.1017/S2040174415001063
}

How to cite TSpace items

Always cite the published version, so the author(s) will receive recognition through services that track citation counts, e.g. Scopus. If you need to cite the page number of the author manuscript from TSpace because you cannot access the published version, then cite the TSpace version in addition to the published version using the permanent URI (handle) found on the record page.

This article was made openly accessible by $\mathbf{U}$ of $T$ Faculty. Please tell us how this access benefits you. Your story matters. 
Short title: Vitamin D and wheezing

Vitamin D exposure during pregnancy, but not early childhood, is associated with risk of childhood wheezing

Laura N. Anderson, PhD; Yang Chen, MSc; Jessica A. Omand, MSc; Catherine S. Birken, MD, MSc, FRCPC; Patricia C. Parkin, MD, FRCPC; Teresa To, PhD; Jonathon L. Maguire, MD, MSc, FRCPC; and the TARGet Kids Collaboration*

From the Division of Pediatric Medicine and the Pediatric Outcomes Research Team, The Hospital for Sick Children, Toronto, Ontario (LNA, CSB, PCP, TT); Department of Pediatrics, St. Michael's Hospital, Toronto, Ontario (LNA, JAO, JLM); The Applied Health Research Centre of the Li Ka Shing Knowledge Institute of St. Michael's Hospital, Toronto, Ontario (YC, JLM);Department of Nutritional Sciences, University of Toronto, Toronto, Ontario (JAO, JLM);Child Health Evaluative Sciences, The Hospital for Sick Children Research Institute, Toronto, Canada (CSB, PCP, TT, JLM); Institute for Health Policy, Management and Evaluation, University of Toronto, Toronto, Ontario (CSB, PCP, TT, JLM); Dalla Lana School of Public Health, University of Toronto, Toronto, Ontario (TT); Department of Pediatrics, Faculty of Medicine, University of Toronto, Toronto, Ontario (CSB, PCP, JLM).

Corresponding author: LN Anderson, The Hospital for Sick Children, Division of Paediatric Medicine, 686 Bay Street, Rm. 109832, Peter Gilgan Centre for Research and Learning,

Toronto, Ontario, M5G 0A4. E-mail: LN.Anderson@utoronto.ca

Word Count of the manuscript text: 2728 
1

2

3

4

\section{Abstract}

The association between vitamin D and wheezing in early childhood is unclear. The primary objective of this study was to evaluate the association between vitamin D exposure, during both pregnancy and childhood, and early childhood wheezing. Secondary objectives were to evaluate the associations between vitamin D exposures and asthma and wheezing severity. We conducted a cohort study of children (0 to 5 years) recruited from 2008-2013 through the TARGet Kids! primary care research network. Vitamin D exposures included: maternal vitamin D supplement use during pregnancy, child vitamin D supplementation, and children's 25-hydroxyvitamin D $(25(\mathrm{OH}) \mathrm{D})$ concentrations. Outcomes measured were parent reported childhood wheezing, diagnosed asthma and wheezing severity. Vitamin D supplement and wheezing data were available on 2478 children and blood samples were available on 1275 children. Adjusted odds ratios (aOR) were estimated using logistic regression adjusted for age, sex, ethnicity, body mass index, birthweight, outdoor play, breastfeeding duration, daycare status, parental smoking and asthma family history. Vitamin D supplementation during pregnancy was associated with lower odds of childhood wheezing ( $\mathrm{aOR}=0.65 ; 95 \% \mathrm{CI}$ : 0.46-0.93). In early childhood, neither 25(OH)D (aOR per 10nmol/L=1.01; 95\% CI: 0.96-1.06) nor vitamin D supplementation $(\mathrm{aOR}=1.00 ; 95 \% \mathrm{CI}: 0.81-1.23)$ were associated with wheezing. No significant associations were observed with diagnosed asthma or wheezing severity. Vitamin D supplementation during pregnancy was associated with reduced odds of wheezing but child vitamin D supplementation and childhood $25(\mathrm{OH}) \mathrm{D}$ were not associated with reduced wheezing. The timing of exposure may be important in understanding the association between vitamin D and childhood wheezing. Key words: vitamin D; asthma; wheezing; child, preschool 


\section{Introduction}

Wheezing and asthma are among the most common health problems in young children and are major causes of emergency department visits and hospitalization in early childhood with significant health services costs. ${ }^{1,2}$ Prevalence estimates for early childhood wheezing in Ontario are 22\%, and range from 10-19\% for asthma. ${ }^{3,4}$ Established risk factors for childhood wheezing include family history of asthma, male gender, exposure to tobacco smoke and environmental allergens. ${ }^{5}$ Emerging evidence suggests that vitamin D may be associated with reduced risk of childhood wheezing and asthma. ${ }^{6-9}$ It is hypothesized that vitamin D may be protective through improved immune function including better response to respiratory infections, decreased airway inflammation, and optimal smooth muscle proliferation contributing to improved lung development. ${ }^{7}$

A growing body of literature suggests that vitamin D exposure in utero may be important in lung development and programming the immune system. ${ }^{10-12}$ Several studies have identified an inverse association between vitamin D intake, from foods or supplements, during pregnancy and childhood wheezing and asthma in offspring. ${ }^{13-17}$ Some of the studies of the association between maternal 25-hydroxyvitamin D $(25(\mathrm{OH}) \mathrm{D})$ concentrations (the preferred vitamin D biomarker) during pregnancy and wheezing or asthma in early childhood have reported an inverse association, ${ }^{18}$ but not all. ${ }^{19-22}$ Two studies of cord blood 25(OH)D concentrations both found evidence of an inverse association with wheezing in young children but no association with asthma in later childhood. ${ }^{23,24}$

The relationship between early childhood $25(\mathrm{OH}) \mathrm{D}$ concentration and wheezing or asthma is less clear. Two large studies found no association between 25(OH)D and adolescent $\operatorname{asthma~}^{25}$ or wheezing ${ }^{26}$, whereas another study found low $25(\mathrm{OH}) \mathrm{D}$ at age 6 years was 
46 associated with increased risk of asthma at age 14 years. ${ }^{27}$ Other studies have suggested that

47 lower 25(OH)D may be associated with wheezing severity, including increased medication use,

48 hospitalization and emergency department visits, among children with asthma older than 5 years

49 of age. ${ }^{28,29}$

The primary objective of this study was to evaluate whether vitamin D exposures,

51 including maternal vitamin D supplementation during pregnancy, child vitamin D

52 supplementation, or child $25(\mathrm{OH}) \mathrm{D}$, were associated with risk of wheezing in early childhood.

53 The secondary objectives were to evaluate if the aforementioned vitamin D exposures were

54 associated with diagnosed asthma, or wheezing severity.

\section{Methods}

56 Participants

57 Healthy children 0 to 5 years (up to 72 months) of age attending scheduled primary care

58 health supervision visits through TARGet Kids! (The Applied Research Group) were recruited

59 between 2008 and 2012 and offered annual follow-up (www.clinicaltrials.gov; NCT01869530).

60 TARGet Kids! is a primary care practice based research network (www.targetkids.ca) and has

61 been described previously. ${ }^{30}$ Children were recruited from 9 pediatric or family practice primary

62 care clinics in Toronto, Canada. Children were excluded who had severe developmental delay or

63 chronic illness (except for asthma) and if they were born less than 32 weeks' gestational age.

64 Study Design

A prospective cohort study was conducted. Baseline was defined as the first visit with questionnaire data on vitamin D supplement intake for all TARGet Kids! participating children

67 and follow-up was defined as the last visit with wheezing data. Blood testing at baseline with

$6825(\mathrm{OH}) \mathrm{D}$ measurement was available on a subset of these children. Informed consent was 
obtained from parents of all participating children and ethical approval was obtained from the Research Ethics Board at The Hospital for Sick Children and St. Michael's Hospital.

\section{Exposure variables}

Three measures of vitamin D exposure were evaluated (hereafter referred to as 'vitamin D exposures'): 1) maternal vitamin D supplementation in pregnancy, 2) child vitamin D supplementation, and 3) child serum $25(\mathrm{OH}) \mathrm{D}$ concentration. Maternal vitamin D supplementation in pregnancy was measured at baseline through a parent-completed standardized data collection form using the question "Did your child's biological mother take any vitamins or supplements during her pregnancy?". Two separate supplement variables were derived during pregnancy: single product vitamin D supplement use and multivitamin use. Data on vitamin D dose was not available for this analysis, but standard prenatal multivitamins contain 400 IU of vitamin D, whereas adult vitamin D supplements typically contain 1000 IU, thus these two sources were evaluated separately. The Canadian Pediatric Society recommends prenatal vitamin D supplementation of 2000 IU/day. ${ }^{31}$

Vitamin D supplementation during childhood was measured at baseline using the question “Does your child take any vitamins or supplements regularly?". One summary variable “child vitamin D supplementation" was derived that included single product vitamin D supplements, multivitamin or multivitamin with iron. In Canada, both children's over-thecounter multivitamins and single product vitamin D supplements usually contain a vitamin D dose of 400 IU.

Child serum 25(OH)D was measured from blood samples collected at baseline by a trained phlebotomist and sent daily to the Mount Sinai Services Laboratory in Toronto (www.mountsinaservices.ca). Serum 25(OH)D was measured using a competitive two-step 
92 chemiluminescence assay (Diasorin LIAISON). This assay was regularly calibrated according to

93 the internationally recognized Vitamin D External Quality Assessment Scheme. ${ }^{32}$ Extensive

94 testing and validation of this assay have been performed and demonstrated an intra-assay

95 imprecision of $7.2 \%$ at a concentration of $213 \mathrm{nmol} / \mathrm{l}$ and an inter-assay imprecision of $4.9 \%$ at

$9632 \mathrm{nmol} / \mathrm{l}, 8.9 \%$ at $77 \mathrm{nmol} / \mathrm{l}$ and $17.4 \%$ at $213 \mathrm{nmol} / \mathrm{l}$, values which are well within acceptable

97 limits for biochemical measurements. ${ }^{33,34}$ For all analysis, serum 25(OH)D was considered as

98 both a continuous variable and categorized as $<50 \mathrm{nmol} / \mathrm{L}$ versus $\geq 50 \mathrm{nmol} / \mathrm{L}$ based on the

99 Institute of Medicine's reference cut-off point. ${ }^{35}$

100

101

102

103

104

105

106

107

108

109

110

\section{Outcome variables}

Three parent-reported outcome measures were evaluated at follow-up. Our primary outcome was parent reported wheezing. Secondary outcomes included parent reported diagnosed asthma and wheezing severity. Wheezing was measured using the International Study for Asthma and Allergy in Childhood (ISAAC) questionnaire by response to the question "Has your child ever had wheezing or whistling in the chest at any time in the past". ${ }^{36}$ Wheezing severity was measured by response to the ISAAC questions "Does your child use asthma medication such as inhalers?" and "During the past 12 months, how many times has your child gone to a hospital emergency room for a wheezing episode?’. Hospitalization and medication use were both categorized as yes or no. Asthma diagnosis was measured by response to the question "Has your child been diagnosed with asthma".

\section{Other variables}

Data on covariates, including potential confounding variables and predictors of the outcome measures, were collected using a parent-completed, standardized questionnaire and physical measurements. Covariates were defined a priori using a causal model and all adjusted 
115 models were fully adjusted for all variables. Covariates included child factors: age, sex, body 116 mass index (BMI), outdoor play, daycare attendance, birth weight and breastfeeding duration.

117 Additional parental or household factors included: median neighbourhood household income,

118 maternal ethnicity, family history of asthma, and parent smoking. Median after tax

119 neighbourhood household income was calculated based on postal code using the Statistics

120 Canada Postal Code Conversion File and data from the 2006 Canadian Census. ${ }^{37}$ Outdoor play

121 was defined as hours per week spent outside playing. Parent asthma was defined as mother or

122 father diagnosed with asthma and parent smoking was defined as smoking of any household

123 member. Child's birthweight and duration of breastfeeding were based on parent recall. Trained

124 research assistants obtained child's current physical measurements including each child's weight

125 and standing height (or length for children under 2 years old). BMI was calculated as weight in

126 kilograms divided by the square of height in metres. ${ }^{38}$ BMI Z-scores were calculated using WHO

127 growth standards. ${ }^{39}$ All covariates were measured at baseline except family history of asthma and 128 parent smoking which were derived from across all visits.

129 Statistical Analysis

Multivariable logistic regression was used to evaluate whether each baseline vitamin D 131 exposure was associated with our primary outcome (wheezing), and both secondary outcomes, 132 (diagnosed asthma and wheezing severity) at follow-up. Adjusted odds ratios (aOR) and 95\% 133 confidence intervals (CI) were reported for all models. Adjusted models included all of the $a$ 134 priori specified, clinically relevant covariates specified above. For the $25(\mathrm{OH}) \mathrm{D}$ models, we also 135 evaluated multivariate models with the month of blood draw included. We tested for 136 multicollinearity using the generalized variance inflation factor (VIF) test. The multiplicative 
137 interactions between all vitamin D exposures and both child sex and family history of asthma 138 were evaluated in all models and $\mathrm{p}<0.05$ was considered statistically significant.

All potential confounders had less than $15 \%$ missing data with the exception of outdoor 140 free play, which had $24 \%$ missing data. To avoid bias, which can be introduced from missing 141 data, multiple imputation was conducted using aregImpute in the R package Hmisc

142 (http://biostat.mc.vanderbilt.edu/wiki/Main/Hmisc). Models were run on 50 imputed data sets 143 using the lrm fitter for logistic regression and the results of the individual analysis were 144 combined to obtain the final estimates. ${ }^{40}$ Data were only imputed for the covariates. Statistical 145 analysis was conducted using SAS statistical software version 9.3 (SAS Institute Inc., Cary, NC, 146 USA) and the R project for statistical computing (http://www.R-project.org).

\section{Results}

A total of 5161 eligible children were recruited into the TARGet Kids! cohort between

149 July 2008 and February 2013. Baseline maternal and child vitamin D supplementation data were 150 available on 5044 children $0-5$ years of age ( $<72$ months) and wheezing data were available from 151 follow-up visits on 2478 children. Baseline 25(OH)D data were available on 2421 children and 152 wheezing data were available at follow-up for 1275 children (Figure 1). The mean time of 153 follow-up for all children was $2.3 \pm 1.2$ years.

154 The baseline characteristics of children with serum $25(\mathrm{OH}) \mathrm{D}$ measures were similar to 155 children without blood measures (Table 1). Among all children, wheezing was reported in $20 \%$ 156 of children and $6 \%$ were diagnosed with asthma. Among the cohort of children with blood 157 testing, the mean $25(\mathrm{OH}) \mathrm{D}$ concentration was $85.9 \pm 28.9 \mathrm{nmol} / \mathrm{L}$ and $6 \%$ of children had 158 concentrations less than $50 \mathrm{nmol} / \mathrm{L}$. 
In our primary analysis, a statistically significant inverse association was observed

160

between mother's vitamin $\mathrm{D}$ supplement use during pregnancy and child wheezing $(\mathrm{aOR}=0.65$;

95\% CI: 0.46-0.93) (Table 2). Maternal multivitamin intake during pregnancy was not associated with wheezing (aOR. $=0.97 ; 95 \%$ CI: 0.69-1.35). Child vitamin D supplement use was also not associated with wheezing $(\mathrm{aOR}=1.00 ; 0.81-1.23)$. In the cohort with blood testing, neither 25(OH)D concentration $(\mathrm{aOR}$ per $10 \mathrm{nmol} / \mathrm{L} 25(\mathrm{OH}) \mathrm{D}=1.01 ; 95 \% \mathrm{CI}$ : 0.96-1.06) nor categorized $25(\mathrm{OH}) \mathrm{D}<50 \mathrm{nmol} / \mathrm{L}$ versus $\geq 50 \mathrm{nmol} / \mathrm{L}(\mathrm{aOR}=1.39 ; 95 \% \mathrm{CI}: 0.78-2.48)$ were associated with wheezing. When we added month of blood draw to the multivariate $25(\mathrm{OH}) \mathrm{D}$ models the aOR did not change.

In our secondary analysis, there were no statistically significant associations between any of the vitamin D exposures and diagnosed asthma (Table 3). The effect estimates for both mother's vitamin D supplement use during pregnancy $(\mathrm{aOR}=0.73 ; 95 \%$ CI $0.40-1.34)$ and multivitamin use during pregnancy $(\mathrm{aOR}=0.80 ; 95 \% \mathrm{CI}: 0.47-1.36)$ and child asthma were less than 1.0, but were not statistically significant. No significant associations were observed for 25(OH)D or vitamin D supplement use in children and diagnosed asthma.

Among 484 children with parent reported diagnosis of wheezing, no statistically significant associations were observed between any vitamin D exposures and hospital emergency room visits or asthma medication use (Table 4). Only 249 of the children with measured $25(\mathrm{OH}) \mathrm{D}$ concentrations had wheezing, and 25(OH)D was also not associated with hospitalization $(\mathrm{aOR}$ per $10 \mathrm{nmol} / \mathrm{L}$ increase $=0.92 ; 95 \% \mathrm{CI}$ : $0.80-1.04)$ or asthma medication use $(\mathrm{aOR}$ per $10 \mathrm{nmol} / \mathrm{L}$ increase $=1.02 ; 95 \% \mathrm{CI}: 0.94-1.11)$. 
No statistically significant interactions $(p<0.05)$ were observed between any of the

181

182

183 vitamin D exposures and either child sex or family history of asthma in relation to wheezing or diagnosed asthma.

\section{Discussion}

We have used prospectively collected data from a cohort of healthy urban preschool children to evaluate whether vitamin D supplement use, during pregnancy or childhood, or child $25(\mathrm{OH}) \mathrm{D}$ concentrations were associated with wheezing, wheezing severity and asthma diagnosis. Use of vitamin D supplements, but not multivitamins, during pregnancy was associated with a 35\% reduced risk of wheezing in early childhood. We found no significant associations between child vitamin D supplementation or $25(\mathrm{OH}) \mathrm{D}$ concentrations and wheezing. Further, none of the vitamin D exposures were significantly associated with either diagnosed asthma or wheezing severity.

Our study is consistent with other studies which have identified that vitamin D intake during pregnancy was associated with decreased risk of wheezing in offspring. ${ }^{13-17}$ Also supporting the hypothesis that vitamin D in early life may be important, two studies of cord blood 25(OH)D concentrations both found evidence of decreased wheezing in young children but not asthma in later childhood. ${ }^{23,24}$ One large prospective cohort study found that maternal 25(OH)D concentrations $<50 \mathrm{nmol} / \mathrm{L}$ at 16-20 weeks' gestation were significantly associated with increased risk of both wheezing and asthma at 6 years of age. ${ }^{18}$ In contrast, other studies of maternal 25(OH)D concentrations during late or mid-pregnancy have not identified an association with wheezing or asthma at age 6 or younger ${ }^{20,21}$ and elsewhere high $25(\mathrm{OH}) \mathrm{D}$ concentrations $(>75 \mathrm{nmol} / \mathrm{L})$ during late pregnancy were associated with increased risk of asthma at age $9 .{ }^{19}$ One small RCT $(n=180)$, with limited statistical power, randomized mothers to 
203 prenatal vitamin D supplementation at 27 weeks gestation and found no association with child 204 wheezing at 3 years of age. ${ }^{41}$ The "relatively deficient" women in this trial were randomized to $205800 \mathrm{IU} /$ day or a single bolus of 200,000 IU and both doses were only modestly associated with 206 cord blood 25(OH)D. ${ }^{41}$

Few studies have evaluated the association between early childhood $25(\mathrm{OH}) \mathrm{D}$ and

208 wheezing outcomes in children less than 6 years of age. ${ }^{42-44}$ One small study of 70 children 1-3 209 years of age in Turkey found 25(OH)D levels were significantly lower in children with wheezing 210 but did not adjust for possible confounders. ${ }^{42}$ Another small study of 30 infants with wheezing 211 and 45 controls in Turkey found no association between $25(\mathrm{OH}) \mathrm{D}$ and recurrent wheezing at a 212 mean age of 12 months. ${ }^{43}$ A case-control study of 103 children with acute wheeze and 101 213 controls less than 4 years of age in Sweden did report a positive association between $25(\mathrm{OH}) \mathrm{D}$ $214<75 \mathrm{nmol} / \mathrm{L}$ and acute wheezing. ${ }^{44}$ None of these studies used a prospective cohort study design 215 and all of them recruited cases from emergency departments ${ }^{44}$ or hospital outpatient clinics ${ }^{42} 43$ 216 which may limit comparison to our prospective cohort study of children recruited from primary 217 care well-child visits.

218 In older children and adolescents, some cross-sectional studies have reported that low $21925(\mathrm{OH}) \mathrm{D}$ concentrations are associated with increased wheezing. ${ }^{45-47}$ However, our findings of a 220 null association are consistent with previous large prospective studies. ${ }^{25-27}$ One of these studies 221 reported a statistically significant association between $25(\mathrm{OH}) \mathrm{D}$ at age 6 years and asthma at age 22214 among males only, ${ }^{27}$ we did not find a sex difference in our population of young children. It is 223 possible that a sex difference may emerge post-puberty. It is also possible that $25(\mathrm{OH}) \mathrm{D}$ levels in 224 our cohort may have been sufficiently high to negate an effect of 25-hydroxyvitamin D on 225 wheezing; only $6 \%$ of children had $25(\mathrm{OH}) \mathrm{D}$ concentrations $<50 \mathrm{nmol} / \mathrm{L}$. This is lower than 
226 estimates from the Canadian Health Measures Survey (CHMS) which found that $15.6 \%$ of

227 children had 25(OH)D concentrations <50nmol/L; however, the CHMS included only older

228 children (6-12 years of age) and was from 2007 to $2009 .{ }^{45}$ There are no national data on young

229 children limiting direct comparison.

The timing of exposure may be important and it is biologically plausible that vitamin D

231 exposure in pregnancy but not early childhood may protect against wheezing. Studies have

232 suggested that vitamin D exposure during pregnancy may be important for lung development or

233 programming of the immune system. ${ }^{10-12}$ Animal studies have found that the offspring of vitamin

234 D deficient mice have impaired lung function and reduced lung volume. ${ }^{48}$ Vitamin D has also

235 been associated with lung cell differentiation and airway branching in vitro. ${ }^{49,50}$ We would

236 expect, however, that the inverse association would be observed for diagnosed asthma as well as

237 wheezing, although only $25 \%$ of children with wheezing were diagnosed with asthma. We may

238 have had limited power to detect an association for asthma given the relatively low prevalence of

239 exposure (6\%); however, established risk factors for asthma, including family history, were

240 associated with both wheezing and asthma in the expected direction (data not shown). Further,

241 we do not know the reason for maternal vitamin D supplements use during pregnancy.

One strength of our study was the use of a standardized questionnaire for the

243 measurement of wheezing. ${ }^{36}$ A 'gold standard' test for the diagnosis of asthma in early childhood

244 remains elusive as spirometry is inaccessible to young children. ${ }^{51}$ Additional strengths included a

245 relatively large sample size, measured $25(\mathrm{OH}) \mathrm{D}$ in young children, and prospective data in the

246 majority of children. Furthermore, detailed questionnaire data were available on vitamin D

247 supplement use and multiple other potential confounders, including established risk factors for 
248 childhood wheezing or asthma allowing us to adjust our models for the major established risk 249 factors for wheezing and asthma.

It is a limitation of our study that we were not able to evaluate incident wheezing as our questionnaire queried "wheezing or whistling in the chest at any time in the past". Maternal report of supplement intake during pregnancy required recall, which may be subject to measurement error and recall bias, although it would not be expected that recall would be differential based on the outcome since wheezing was measured at a subsequent visit. We did not have access to maternal $25(\mathrm{OH}) \mathrm{D}$ during pregnancy and cannot rule out the possibility that the inverse association between maternal vitamin D supplementation during pregnancy and wheezing in early childhood may be due to residual confounding. We did, however, adjust for numerous potential confounders and our fully adjusted models were very similar to the unadjusted results. Further, we did not observe a similar association with prenatal multivitamin use which generally contains less vitamin D, but may be expected to be associated with wheezing if the observed association was due to confounding by some unmeasured characteristic associated with supplement use.

Despite the increasing incidence of asthma and burden on the health care system, there are relatively few modifiable risk factors for child wheezing. Although we did not find an association between $25(\mathrm{OH}) \mathrm{D}$ in early childhood and wheezing risk or severity, our results do support the hypothesis that vitamin D exposure in utero may protect against early childhood wheezing. Given that only $12 \%$ of mothers reported taking a vitamin D supplement during pregnancy this may be a modifiable factor to reduce childhood wheezing. A well designed randomized controlled trial of vitamin D supplementation during pregnancy and wheezing outcomes in childhood would be helpful to confirm or refute our findings. 
Anderson et al.

271 
272 Acknowledgements: The authors thank all participating families for their time and involvement 273 in TARGet Kids! and are grateful to all practitioners who are currently involved in the TARGet

274 Kids! research network. Steering Committee: Tony Barozzino, Brian Chisamore, Mark 275 Feldman, Moshe Ipp. Research Team: Charmaine Camacho, Diviya Elango, Julie DeGroot, 276 Shanique Edwards, Nadia Kabir, Marina Khovratovich, Tarandeep Malhi, Juela Sejdo, Laurie 277 Thompson, Mandy Tran. Applied Health Research Centre: Gerald Lebovic, Magda Melo, 278 Patricia Nguyen. Mount Sinai Services Laboratory: Azar Azad.

279 *TARGet Kids! Collaboration - Scientific Committee: Kawsari Abdullah, Laura N. Anderson, 280 Catherine S. Birken, Cornelia M. Borkhoff, Sarah Carsley, Yang Chen, Matthew D’Ascanio, 281 Mikael Katz-Lavigne, Kanthi Kavikondala, Grace Jieun Lee, Jonathon L. Maguire, Jessica 282 Omand, Patricia C. Parkin, Navindra Persaud, Meta van den Heuvel, Weeda Zabih; Site 283 Investigators: Jillian Baker, Tony Barozzino, Joey Bonifacio, Douglas Campbell, Sohail 284 Cheema, Brian Chisamore, Karoon Danayan, Paul Das, Mary Beth Derocher, Anh Do, Michael 285 Dorey, Sloane Freeman, Keewai Fung, Charlie Guiang, Curtis Handford, Hailey Hatch, Sheila 286 Jacobson, Tara Kiran, Holly Knowles, Bruce Kwok, Sheila Lakhoo, Margarita Lam-Antoniades, 287 Eddy Lau, Fok-Han Leung, Jennifer Loo, Sarah Mahmoud, Rosemary Moodie, Julia Morinis, 288 Sharon Naymark, Patricia Neelands, James Owen, Michael Peer, Marty Perlmutar, Navindra 289 Persaud, Andrew Pinto, Michelle Porepa, Nasreen Ramji, Noor Ramji, Alana Rosenthal, Janet 290 Saunderson, Rahul Saxena, Michael Sgro, Susan Shepherd, Barbara Smiltnieks, Carolyn Taylor, 291 Thea Weisdors, Sheila Wijayasinghe, Peter Wong, Ethel Ying, Elizabeth Young.

Financial Support: This work was supported by the Canadian Institutes of Health Research.

294 Funding agencies had no role in the design and conduct of the study, collection, management, 
295 analyses or interpretation of the results of this study or in the preparation, review, or approval of 296 the manuscript.

298 Conflicts of Interest: None

299

300 Ethical Standards: The authors assert that all procedures contributing to this work comply with 301 the ethical standards of the relevant national guidelines on human experimentation (Canadian 302 Tri-Council Policy Statement: Ethical Conduct for Research Involving Humans) and with the 303 Helsinki Declaration of 1975, as revised in 2008, and has been approved by the institutional 304 committees (The Research Ethics Board at The Hospital for Sick Children and St. Michael's 305 Hospital, Toronto, Ontario). 


\section{REFERENCES}

1. To T, Dell S, Dick P, Cicutto L. The burden of illness experienced by young children associated with asthma: a population-based cohort study. J Asthma. 2008;45(1), 45-49.

2. Krahn MD, Berka C, Langlois P, Detsky AS. Direct and indirect costs of asthma in Canada, 1990. Can Med Assoc J. 1996;154(6), 821-831.

3. Crighton EJ, Feng J, Gershon A, Guan J, To T. A spatial analysis of asthma prevalence in Ontario. Can J Public Health. 2012;103(5), e384-389.

4. Garner R, Kohen D. Changes in the prevalence of asthma among Canadian children. Health Rep. 2008;19(2), 45-50.

5. Sears MR. Epidemiology of childhood asthma. Lancet. 1997;350(9083), 1015-1020.

6. Ginde AA, Mansbach JM, Camargo CA, Jr. Vitamin D, respiratory infections, and asthma. Curr Allergy Asthma Rep. 2009;9(1), 81-87.

7. Litonjua AA. Vitamin D deficiency as a risk factor for childhood allergic disease and asthma. Curr Opin Allergy Clin Immunol. 2012;12(2), 179-185.

8. Hollams EM. Vitamin D and atopy and asthma phenotypes in children. Curr Opin Allergy Clin Immunol. 2012;12(3), 228-234.

9. Lau S. What is new in the prevention of atopy and asthma? Curr Opin Allergy Clin Immunol. 2013;13(2), 181-186.

10. Yong SB, Wu CC, Wang L, Yang KD. Influence and mechanisms of maternal and infant diets on the development of childhood asthma. Pediatr Neonatol. 2013;54(1), 5-11.

11. De Luca G, Olivieri F, Melotti G, Aiello G, Lubrano L, Boner AL. Fetal and early postnatal life roots of asthma. J Matern Fetal Neonatal Med. 2010;23 Suppl 3, 80-83.

12. Devereux G. Early life events in asthma--diet. Pediatr Pulmonol. 2007;42(8), 663-673.

13. Devereux G, Litonjua AA, Turner SW, et al. Maternal vitamin D intake during pregnancy and early childhood wheezing. Am J Clin Nutr. 2007;85(3), 853-859.

14. Miyake Y, Sasaki S, Tanaka K, Hirota Y. Dairy food, calcium and vitamin D intake in pregnancy, and wheeze and eczema in infants. Eur Respir J. 2010;35(6), 1228-1234.

15. Erkkola $\mathrm{M}$, Kaila $\mathrm{M}, \mathrm{Nwaru} \mathrm{BI}$, et al. Maternal vitamin $\mathrm{D}$ intake during pregnancy is inversely associated with asthma and allergic rhinitis in 5-year-old children. Clin Exp Allergy. 2009;39(6), 875-882.

16. Camargo CA, Rifas-Shiman SL, Litonjua AA, et al. Maternal intake of vitamin D during pregnancy and risk of recurrent wheeze in children at 3 y of age. Am J Clin Nutr. 2007;85(3), 788-795.

17. Maslova E, Hansen S, Jensen CB, Thorne-Lyman AL, Strøm M, Olsen SF. Vitamin D intake in midpregnancy and child allergic disease - a prospective study in 44,825 Danish mother-child pairs. BMC Pregnancy Childbirth. 2013;13, 199.

18. Zosky GR, Hart PH, Whitehouse AJ, et al. Vitamin D deficiency at 16 to 20 weeks' gestation is associated with impaired lung function and asthma at 6 years of age. Ann Am Thorac Soc. 2014;11(4), 571-577.

19. Gale CR, Robinson SM, Harvey NC, et al. Maternal vitamin D status during pregnancy and child outcomes. Eur J Clin Nutr. 2008;62(1), 68-77.

20. Pike KC, Inskip HM, Robinson S, et al. Maternal late-pregnancy serum 25-hydroxyvitamin D in relation to childhood wheeze and atopic outcomes. Thorax. 2012;67(11), 950-956.

21. Morales E, Romieu I, Guerra S, et al. Maternal vitamin D status in pregnancy and risk of lower respiratory tract infections, wheezing, and asthma in offspring. Epidemiology. 2012;23(1), 64-71. 
22. Magnus MC, Stene LC, Håberg SE, et al. Prospective study of maternal mid-pregnancy 25hydroxyvitamin D level and early childhood respiratory disorders. Paediatr Perinat Epidemiol. 2013;27(6), 532-541.

23. Baïz N, Dargent-Molina P, Wark JD, Souberbielle JC, Annesi-Maesano I, Group EM-CCS. Cord serum 25-hydroxyvitamin $D$ and risk of early childhood transient wheezing and atopic dermatitis. J Allergy Clin Immunol. 2014;133(1), 147-153.

24. Camargo CA, Ingham T, Wickens $K$, et al. Cord-blood 25-hydroxyvitamin D levels and risk of respiratory infection, wheezing, and asthma. Pediatrics. 2011;127(1), e180-187.

25. Gergen PJ, Teach SJ, Mitchell HE, et al. Lack of a relation between serum 25-hydroxyvitamin D concentrations and asthma in adolescents. Am J Clin Nutr. 2013;97(6), 1228-1234.

26. Tolppanen AM, Sayers A, Granell R, Fraser WD, Henderson J, Lawlor DA. Prospective association of 25-hydroxyvitamin $\mathrm{d} 3$ and $\mathrm{d} 2$ with childhood lung function, asthma, wheezing, and flexural dermatitis. Epidemiology. 2013;24(2), 310-319.

27. Hollams EM, Hart PH, Holt BJ, et al. Vitamin D and atopy and asthma phenotypes in children: a longitudinal cohort study. Eur Respir J. 2011;38(6), 1320-1327.

28. Brehm JM, Acosta-Pérez E, Klei L, et al. Vitamin D insufficiency and severe asthma exacerbations in Puerto Rican children. Am J Respir Crit Care Med. 2012;186(2), 140-146.

29. Brehm JM, Schuemann B, Fuhlbrigge AL, et al. Serum vitamin D levels and severe asthma exacerbations in the Childhood Asthma Management Program study. J Allergy Clin Immunol. 2010;126(1), 52-58.e55.

30. Carsley S, Borkhoff CM, Maguire JL, et al. Cohort Profile: The Applied Research Group for Kids (TARGet Kids!). Int J Epidemiology. 2014.

31. Godel JC, Canadian Paediatric Society FN, Inuit and Metis Health Committee. Vitamin D supplementation: Recommendations for Canadian mothers and infants. Paediatr Child Health. 2007;12(7), 583-589.

32. Carter GD, Carter R, Jones J, Berry J. How accurate are assays for 25-hydroxyvitamin D? Data from the international vitamin D external quality assessment scheme. Clin Chem. 2004;50(11), 2195-2197.

33. Maunsell Z, Wright DJ, Rainbow SJ. Routine isotope-dilution liquid chromatography-tandem mass spectrometry assay for simultaneous measurement of the 25-hydroxy metabolites of vitamins D2 and D3. Clin Chem. 2005;51(9), 1683-1690.

34. Singh RJ, Taylor RL, Reddy GS, Grebe SK. C-3 epimers can account for a significant proportion of total circulating 25 -hydroxyvitamin $\mathrm{D}$ in infants, complicating accurate measurement and interpretation of vitamin D status. J Clin Endocrinol Metab. 2006;91(8), 3055-3061.

35. Committee to Review Dietary Reference Intakes for Vitamin D and Calcium loM. Dietary Reference Intakes for Calcium and Vitamin D Washington, DC: 2010.

36. Asher MI, Keil U, Anderson HR, et al. International Study of Asthma and Allergies in Childhood (ISAAC): rationale and methods. Eur Respir J. 1995;8(3), 483-491.

37. Wilkins R. PCCF+ Version 5E User's Guide. Automated Geographic Coding Based on the Statistics Canada Postal Code Conversion Files, Including Postal Codes through March 2009. Ottawa: 2009.

38. Mei Z, Grummer-Strawn LM, Pietrobelli A, Goulding A, Goran MI, Dietz WH. Validity of body mass index compared with other body-composition screening indexes for the assessment of body fatness in children and adolescents. Am J Clin Nutr. 2002;75(6), 978-985.

39. Group WMGRS. WHO Child Growth Standards based on length/height, weight and age. Acta Paediatr Suppl. 2006;450, 76-85.

40. Little RJA, Rubin DB. Statistical analysis with missing data, 2nd edn, 2002. Wiley: Hoboken, NJ. 
41. Goldring ST, Griffiths CJ, Martineau AR, et al. Prenatal vitamin d supplementation and child respiratory health: a randomised controlled trial. PloS one. 2013;8(6), e66627.

42. Demirel S, Guner SN, Celiksoy MH, Sancak R. Is vitamin D insufficiency to blame for recurrent wheezing? Int Forum Allergy Rhinol. 2014;4(12), 980-985.

43. Ozaydin E, Butun MF, Cakir BC, Kose G. The association between vitamin d status and recurrent wheezing. Indian J Pediatrics. 2013;80(11), 907-910.

44. Stenberg Hammar K, Hedlin G, Konradsen JR, et al. Subnormal levels of vitamin D are associated with acute wheeze in young children. Acta Paediatr Suppl. 2014;103(8), 856-861.

45. Niruban SJ, Alagiakrishnan K, Beach J, Senthilselvan A. Association of vitamin D with respiratory outcomes in Canadian children. Eur J Clin Nutr. 2014;68(12), 1334-1340.

46. Bener A, Ehlayel MS, Bener HZ, Hamid Q. The impact of Vitamin D deficiency on asthma, allergic rhinitis and wheezing in children: An emerging public health problem. J Family Community Med. 2014;21(3), 154-161.

47. Uysalol M, Uysalol EP, Yilmaz $Y$, et al. Serum level of vitamin D and trace elements in children with recurrent wheezing: a cross-sectional study. BMC pediatrics. 2014;14, 270.

48. Zosky GR, Berry LJ, Elliot JG, James AL, Gorman S, Hart PH. Vitamin D deficiency causes deficits in lung function and alters lung structure. Am J Respir Crit Care Med. 2011;183(10), 1336-1343.

49. Nguyen $\mathrm{M}$, Trubert CL, Rizk-Rabin $\mathrm{M}$, et al. 1,25-Dihydroxyvitamin D3 and fetal lung maturation: immunogold detection of VDR expression in pneumocytes type II cells and effect on fructose 1,6 bisphosphatase. J Steroid Biochem Mol Biol. 2004;89-90(1-5), 93-97.

50. Nguyen TM, Guillozo H, Marin L, Tordet C, Koite S, Garabedian M. Evidence for a vitamin D paracrine system regulating maturation of developing rat lung epithelium. Am J Physiol. 1996;271(3 Pt 1), L392-399.

51. Diagnosis of asthma. Can Med Assoc J. 2005;173(6 Suppl), S15-19. 
Table 1: TARGet Kids! baseline population characteristics

\begin{tabular}{|c|c|c|}
\hline & $\begin{array}{l}\text { All children } \\
(\mathbf{n}=\mathbf{2 4 7 8})\end{array}$ & $\begin{array}{c}\text { Children with } 25(\mathrm{OH}) \mathrm{D} \\
(\mathbf{n = 1 2 7 5})\end{array}$ \\
\hline & Mean $\pm S D$ & Mean $\pm S D$ \\
\hline Age (months) & $29.3 \pm 17.9$ & $30.5 \pm 18.3$ \\
\hline $25(\mathrm{OH}) \mathrm{D}(\mathrm{nmol} / \mathrm{L})$ & N/A & $85.9 \pm 28.9$ \\
\hline BMI z-score & $0.10 \pm 1.03$ & $0.08 \pm 1.03$ \\
\hline Outdoor free play (minutes/day) & $56.6 \pm 59.4$ & $60.6 \pm 56.0$ \\
\hline Birthweight (kilograms) & $3.3 \pm 0.7$ & $3.3 \pm 0.7$ \\
\hline Neighborhood Income (CDN\$) & $60,686 \pm 26,861$ & $59,392 \pm 25,450$ \\
\hline \multirow[t]{2}{*}{ Breastfed duration (months) } & $10.1 \pm 6.7$ & $10.2 \pm 6.8$ \\
\hline & No. $(\%)^{a}$ & No. $(\%)^{a}$ \\
\hline \multicolumn{3}{|l|}{ Sex } \\
\hline Female & $1196(48 \%)$ & $624(49 \%)$ \\
\hline Male & $1282(52 \%)$ & $651(51 \%)$ \\
\hline \multicolumn{3}{|l|}{ Maternal Ethnicity } \\
\hline European & $1719(72 \%)$ & $837(68 \%)$ \\
\hline East Asian & $179(7 \%)$ & $94(8 \%)$ \\
\hline Southeast/South Asian & $186(8 \%)$ & $114(9 \%)$ \\
\hline Other & $312(13 \%)$ & $179(15 \%)$ \\
\hline \multicolumn{3}{|l|}{ Family history of asthma - mother } \\
\hline No & $2219(91 \%)$ & $1145(91 \%)$ \\
\hline Yes & $224(9 \%)$ & $113(9 \%)$ \\
\hline \multicolumn{3}{|l|}{ Family history of asthma - father } \\
\hline No & $2251(92 \%)$ & $1161(92 \%)$ \\
\hline Yes & $193(8 \%)$ & $97(8 \%)$ \\
\hline \multicolumn{3}{|l|}{ Attendance at daycare } \\
\hline No & $1417(59 \%)$ & $745(60 \%)$ \\
\hline Yes & $980(41 \%)$ & $495(40 \%)$ \\
\hline \multicolumn{3}{|l|}{ Parental Smoking } \\
\hline No & $2166(88 \%)$ & $1104(87 \%)$ \\
\hline Yes & $309(12 \%)$ & $171(13 \%)$ \\
\hline \multicolumn{3}{|l|}{ Serum $25(\mathrm{OH}) \mathrm{D}$} \\
\hline$<50 \mathrm{nmol} / \mathrm{L}$ & N/A & $73(6 \%)$ \\
\hline$\geq 50 \mathrm{nmol} / \mathrm{L}$ & & $1202(94 \%)$ \\
\hline \multicolumn{3}{|l|}{ Child vitamin D supplementation } \\
\hline No & $1272(51 \%)$ & $565(44 \%)$ \\
\hline Yes & $1206(49 \%)$ & $710(56 \%)$ \\
\hline \multicolumn{3}{|c|}{ Vitamin D supplement use during pregnancy } \\
\hline No & $2074(88 \%)$ & $1041(86 \%)$ \\
\hline Yes & $280(12 \%)$ & $171(14 \%)$ \\
\hline \multicolumn{3}{|l|}{ Multivitamin use during pregnancy } \\
\hline No & $261(11 \%)$ & $91(8 \%)$ \\
\hline Yes & $2100(89 \%)$ & $1122(93 \%)$ \\
\hline Wheezing ${ }^{b}$ & & \\
\hline
\end{tabular}




\begin{tabular}{lcc}
\hline No & $1985(80 \%)$ & $1020(80 \%)$ \\
Yes & $493(20 \%)$ & $255(20 \%)$ \\
Diagnosed asthma $^{\mathrm{b}}$ & & \\
$\quad$ No & $2289(94 \%)$ & $1186(95 \%)$ \\
$\quad$ Yes & $148(6 \%)$ & $66(5 \%)$ \\
Hospital emergency department visit & \\
$\quad$ No & $404(83 \%)$ & $210(84 \%)$ \\
$\quad$ Yes & $80(17 \%)$ & $39(16 \%)$ \\
Use of asthma medication such as inhalers & & \\
$\quad$ No & $258(54 \%)$ & $138(56 \%)$ \\
Yes & $221(46 \%)$ & $110(44 \%)$ \\
\hline
\end{tabular}

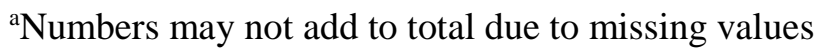

${ }^{b}$ Parent reported wheezing and diagnosed asthma at follow-up.

'Severity among children with wheezing at follow-up only; $n=484$ for supplements and $n=249$ for 25(OH)D. 
Table 2: Logistic regression models for vitamin $D$ exposures and wheezing at follow-up $(n=2478)$

\begin{tabular}{|c|c|c|}
\hline Vitamin D exposure variables at baseline & $\begin{array}{c}\text { Unadjusted analysis } \\
\text { OR }(95 \% \mathrm{CI})\end{array}$ & $\begin{array}{c}\text { Adjusted analysis }{ }^{\mathrm{a}} \\
\text { OR }(95 \% \mathrm{CI})\end{array}$ \\
\hline \multicolumn{3}{|l|}{ Vitamin D supplement use during pregnancy } \\
\hline No & 1.00 & 1.00 \\
\hline Yes & $0.72(0.51-1.00)$ & $0.65(0.46-0.93)$ \\
\hline \multicolumn{3}{|l|}{ Multivitamin use during pregnancy } \\
\hline No & 1.00 & 1.00 \\
\hline Yes & $1.02(0.74-1.41)$ & $0.97(0.69-1.35)$ \\
\hline \multicolumn{3}{|l|}{ Child vitamin D supplementation } \\
\hline No & 1.00 & 1.00 \\
\hline Yes & $1.00(0.82-1.22)$ & $1.00(0.81-1.23)$ \\
\hline $25(\mathrm{OH}) \mathrm{D}$ per $10 \mathrm{nmol} / \mathrm{L}$ units $^{\mathrm{b}}$ & $1.01(0.96-1.06)$ & $1.01(0.96-1.06)$ \\
\hline \multicolumn{3}{|l|}{ Categorical $25(\mathrm{OH}) \mathrm{D}^{\mathrm{b}}$} \\
\hline$<50 \mathrm{nmol} / \mathrm{L}$ & $1.33(0.77-2.31)$ & $1.39(0.78-2.48)$ \\
\hline$>50 \mathrm{nmol} / \mathrm{L}$ & 1.00 & 1.00 \\
\hline
\end{tabular}

Bold $=$ statistically significant findings at $\mathrm{p}<0.05$

${ }^{a}$ Adjusted for child sex, family income, smoker in household, maternal ethnicity, child in licensed daycare, age in months, zBMI, birth weight, hours of outdoor free play, breastfeeding duration and family history of asthma (both mother and father). All covariates were measured at baseline except family history of asthma and parent smoking which were derived from across all visits.

${ }^{\mathrm{b}}$ Serum measured $25(\mathrm{OH}) \mathrm{D}$ was available on 1275 children. 
Table 3: Logistic regression models for vitamin $D$ exposures and diagnosed asthma at follow-up $(n=2437)$

\begin{tabular}{lcc}
\hline \multicolumn{1}{c}{ Vitamin D exposure variables at baseline } & $\begin{array}{c}\text { Unadjusted analysis } \\
\text { OR }(95 \% \mathrm{CI})\end{array}$ & $\begin{array}{c}\text { Adjusted analysis } \\
\text { OR }(95 \% \mathrm{CI})\end{array}$ \\
\hline $\begin{array}{l}\text { Vitamin D supplement use during pregnancy } \\
\quad \text { No }\end{array}$ & 1.00 & 1.00 \\
$\quad$ Yes & $0.78(0.43-1.40)$ & $0.73(0.40-1.34)$ \\
Multivitamin use during pregnancy & 1.00 & 1.00 \\
$\quad$ No & $0.83(0.50-1.38)$ & $0.80(0.47-1.36)$ \\
$\quad$ Yes & & \\
Child vitamin D supplementation & 1.00 & 1.00 \\
$\quad$ No & $0.89(0.64-1.24)$ & $0.82(0.58-1.16)$ \\
$\quad$ Yes & $0.94(0.85-1.03)$ & $0.93(0.85-1.03)$ \\
25(OH)D per 10nmol/L units ${ }^{\mathrm{b}}$ & & $1.75(0.70-4.40)$ \\
Categorical 25(OH)D & $1.73(0.72-4.14)$ & 1.00 \\
$<50 \mathrm{nmol} / \mathrm{L}$ & 1.00 & \\
$>50 \mathrm{nmol} / \mathrm{L}$ & &
\end{tabular}

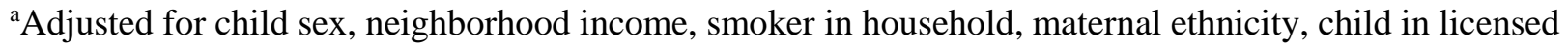
daycare, child age in months, zBMI, birthweight, hours of outdoor free play, and breastfeeding duration and family history of asthma. All covariates were measured at baseline except family history of asthma and parent smoking which were derived from across all visits.

${ }^{\mathrm{b}}$ Serum measured $25(\mathrm{OH}) \mathrm{D}$ was available on 1252 children. 
Table 4: Logistic regression models for vitamin D exposures and wheezing severity among children with wheezing $(n=484)$

\begin{tabular}{|c|c|c|}
\hline Vitamin D exposure variables at baseline & $\begin{array}{l}\text { Unadjusted analysis } \\
\text { OR }(95 \% \mathrm{CI})\end{array}$ & $\begin{array}{c}\text { Adjusted analysis }^{2} \\
\text { OR }(95 \% \mathrm{CI}) \\
\end{array}$ \\
\hline \multicolumn{3}{|l|}{$\begin{array}{l}\text { Hospital emergency department visit for a } \\
\text { wheezing episode over the past } 12 \text { months }\end{array}$} \\
\hline \multicolumn{3}{|l|}{ Vitamin D supplement use during pregnancy } \\
\hline No & 1.00 & 1.00 \\
\hline Yes & $1.29(0.59-2.80)$ & $0.92(0.40-2.13)$ \\
\hline \multicolumn{3}{|l|}{ Multivitamin use during pregnancy } \\
\hline No & 1.00 & 1.00 \\
\hline Yes & $1.13(0.51-2.50)$ & $1.00(0.42-2.35)$ \\
\hline \multicolumn{3}{|l|}{ Child vitamin D supplementation } \\
\hline No & 1.00 & 1.00 \\
\hline Yes & $0.95(0.59-1.53)$ & $1.06(0.63-1.77)$ \\
\hline $25(\mathrm{OH}) \mathrm{D}$ per $10 \mathrm{nmol} / \mathrm{L}$ units $^{\mathrm{b}}$ & $0.89(0.79-1.01)$ & $0.92(0.80-1.04)$ \\
\hline \multicolumn{3}{|l|}{ Categorical 25(OH)D } \\
\hline$<50 \mathrm{nmol} / \mathrm{L}$ & $2.23(0.75-6.65)$ & $1.57(0.48-5.17)$ \\
\hline$>50 \mathrm{nmol} / \mathrm{L}$ & 1.00 & 1.00 \\
\hline \multicolumn{3}{|l|}{ Use of asthma medication such as inhalers } \\
\hline \multicolumn{3}{|l|}{ Vitamin D supplement use during pregnancy } \\
\hline No & 1.00 & 1.00 \\
\hline Yes & $0.98(0.52-1.85)$ & $0.91(0.46-1.79)$ \\
\hline \multicolumn{3}{|l|}{ Multivitamin use during pregnancy } \\
\hline No & 1.00 & 1.00 \\
\hline Yes & $0.82(0.45-1.50)$ & $0.82(0.44-1.53)$ \\
\hline \multicolumn{3}{|l|}{ Vitamin D supplement use in children } \\
\hline No & 1.00 & 1.00 \\
\hline Yes & $0.99(0.69-1.42)$ & $0.94(0.64-1.37)$ \\
\hline $25(\mathrm{OH}) \mathrm{D}$ per $10 \mathrm{nmol} / \mathrm{L}$ units $^{\mathrm{b}}$ & $1.02(0.94-1.10)$ & $1.02(0.94-1.11)$ \\
\hline \multicolumn{3}{|l|}{ Categorical 25(OH)D } \\
\hline$<50 \mathrm{nmol} / \mathrm{L}$ & $1.00(0.38-2.64)$ & $0.94(0.33-2.71)$ \\
\hline$>50 \mathrm{nmol} / \mathrm{L}$ & 1.00 & 1.00 \\
\hline
\end{tabular}

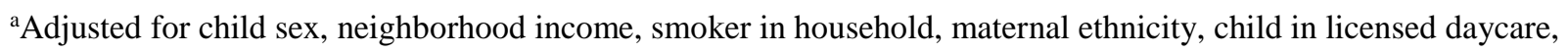
age in months, zBMI, birth weight, hours of outdoor free play, and breastfeeding duration. All covariates were measured at baseline except family history of asthma and parent smoking which were derived from across all visits.

${ }^{\mathrm{b}}$ Serum measured 25(OH)D was available on 249 children. 


\section{Figure 1. Identification of the study cohort.}

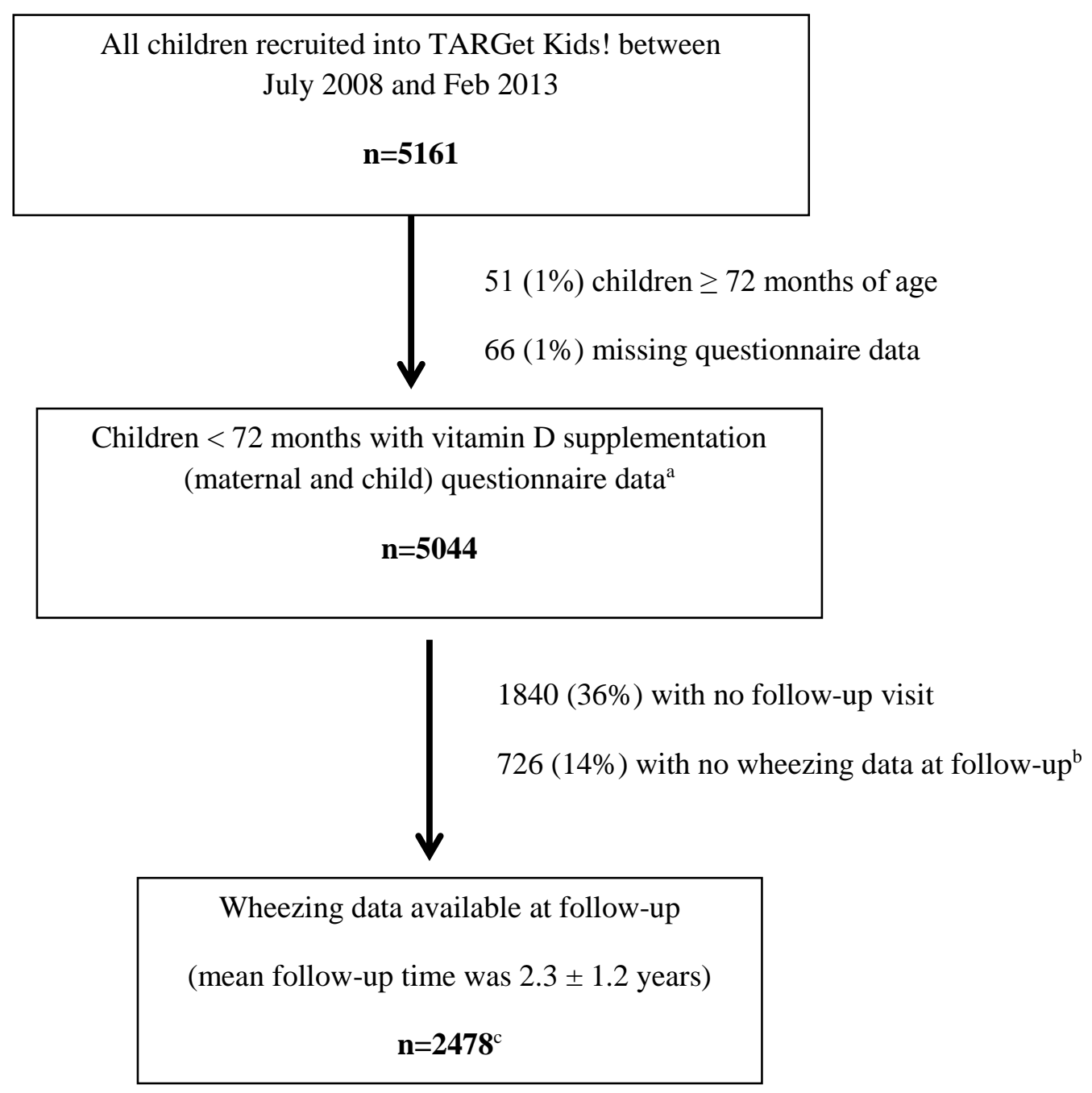

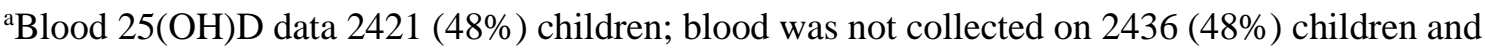
$187(4 \%)$ had no measure of $25(\mathrm{OH}) \mathrm{D}$

${ }^{\text {b} W h e e z i n g ~ d a t a ~ w e r e ~ n o t ~ c o l l e c t e d ~ p r i o r ~ t o ~} 2011$

${ }^{\mathrm{c}} 1275(51 \%)$ with blood 25(OH)D data 